\title{
AN EMPIRICAL ANALYSIS OF F ACTORS PROMOTING JAPANESE ADSL (ASYNCHRONOUS DIGITAL SUBSCRIBER LINE)
}

\author{
Masatsugu Tsuji* \\ Graduate School of Applied Informatics, University of Hyogo \\ 1-3-3, Higashi-Kawasaki-cho, Chuou-ku, Kobe 650-0044, JAPN \\ Department of Urban Studies, National Cheng Kung University, Taiwan \\ e-mail: tsuji@ai.u-hyogo.ac.jp \\ Masaru Ogawa \\ Faculty of Business Management, \\ Kobe Gakuin University \\ Kobe, Japan \\ e-mail: $\underline{\text { czk07133@nifty.com }}$
}

\begin{abstract}
The factors of Japanese ADSL diffusion can be summarized as follows: (a) deregulations including competition policy; (b) competition among ISPs; (c) technological developments, and (c) others. Deregulations include the following examples: (i) collocation rules; (ii) disclosure of ADSL capacity information; (iii) unbundling; and (iv) charges for dry copper and interconnection. New entrants with extremely new charges, such as Yahoo! BB, are examples of (b). An example of (c) is ADSL connection speed; the services currently offered to subscribers are $50 \mathrm{Mbps}$.This paper heuristically analyzes using AHP the degree to which above four factors contributed to ADSL growth in Japan.
\end{abstract}

Keywords: ADSL, consumers'surplus, unbundling, collocation

\section{Introduction}

The environments of the Japanese ADSL market were not initially favorable: the ADSL service in Japan was introduced later than in Korea, U.S. and other countries, which caused Japanese ADSL penetration to lag behind. This was considered a symbol of Japan's delay in embracing the so-called IT Revolution. Since then, however, a lot of effort has been made by both private and public sectors to catch up. Among these were efforts to promote competition in the market, including deregulations in the following areas: (i) unbundling; (ii) collocation rules; (iii) disclosure of ADSL capacity information; and (iv) charges for dry copper and dark fiber for interconnection. Because of these deregulations, new entrants emerged in the market, with Yahoo! BB is representing a typical example. When Yahoo! BB entered the market, it offered almost half price of others. Since them, fierce price competition has been in effect. In addition to charges, competition occurred in various services. It was Yahoo! BB that started free services such as offering modem, on-site installment, and a three month initial trial. In this paper, we summarize the factors to promote ADSL as follows: (a) deregulations; (b) competition among ISPs; (c) technology; and (d) others such as digital content. And this paper heuristically analyzes the degree to which the above four factors contributed to ADSL growth in Japan. We will present concrete quantitative figures of the factors' contributions from 2001 to 2004, measured in terms of consumers' surplus, which is indicated the area below the demand curve. The methodology we utilize in our analysis is AHP. First, we measure the size of consumers' surplus for each year by estimating the demand function of ADSL. Consumers' surpluses obtained are US\$2.8 million in 2001FY, US\$0.6 million in 2002FY, US\$1.7 million in 2003FY, and

\footnotetext{
* Corresponding author
} 
US\$0.2 million in 2004FY. We seek to attribute these consumers' surpluses to the above four factors. In so doing, we utilize AHP, drawing on our interviews with four major ISPs -- NTT locals, Yahoo! BB, eAccess, and ACCA Networks - in which we asked each about the relative importance of the above four factors for each year. Finally, by summing the weights of the factors for the four ISPs, we obtain the weights for the market as a whole, and consumers' surplus is thus attributed to the four factors. The exact economic effects of deregulations, competition, technological development, and others are judged to be \$1.6, \$2.2, \$1.1 and \$0.6 million for 2001-2004, respectively.

Although there are many previous researches on broadband technology, we have few researches on empirical studies of its development. Eisner and Waldon (2001), Kridel, Rappoport and Taylor (2001), Sidak, Crandall and Singer (2002) utilized discrete choice methods to analyze competition of broadband market in US. The discrete choice method is readily available because they have plenty individual data in US. In Japan, however, we can hardly apply discrete choice method because of the lack of data. This paper, therefore, utilizes AHP, which does not require large data but produces fruitful results.

\section{Estimation of ADSL demand function}

\subsection{Data}

The economic effects of four factors in this paper are expressed in terms of consumer demand; this estimation requires us to estimate the demand function of the ADSL services. The relevant data from FY 2001 through August 2004 were obtained from the Ministry of Internal Affairs and Communications (MIC). In Figure 1, ADSL charges, which are converted to Yen per Mbps unit, are shown on the left axis. The various drops in these charges, at beginning of 2002, the beginning at of 2003, and August 2003, are thought to be results of factors such as deregulations, competitions, and technological developments. On the other hand, the rate of its increase in the number of new ADSL subscribers, increased until the end of 2002, and then decreased gradually. Before the end of 2002, three sharp increases in new subscriber's number were observed -- before June 2001, from September 2001 to January 2002, and from October 2002 to January 2003. We thus attempt to identify relative contribution of the various factors to these periods of new subscriber's increase.

\subsection{ADS L demand function}

First, let us estimate the size of the consumers' surplus that emerged during the analysis period. In general, the demand function can be written as:

$$
x=x(p, M, f)
$$

where $p$ stands for real price, $M$ for real income, and $f$ for shift parameter. Therefore the estimate equation for the ADSL demand function can be expressed as follows:

$$
x=\beta_{0}+\beta_{1} p+\beta_{2} M
$$

In this paper, we assume that there is no shift factor. For the sample period, we take the 44 periods from January 2001when NTT started its DSL services, to August 2004 when it stopped the announcing of month-end subscriber numbers. We present all variables on a logarithm scale in order to stabilize the variable. In this case, the demand for services is regarded as the ADSL connection services of one month, if sign-ups and cancellations during the month are disregarded. The number of ADSL contracts at each month-end, which was announced from Ministry of Internal Affairs and Communications, is assumed to be the amount of the demand. For charges, we take the connection service charges for a month at the month-end, to ensure consistency with the demand. The data is comes from the change in monthly fees for Flet's ADSL connection services. We calculated the fee in terms of Yen per $1 \mathrm{Mbps}$, so as to compensate for the effect of across-the-band improvement of connection speed. In addition, we adjusted 
Yen values by the Consumer Price Index for each year. As for the income, we broke down the seasonal adjusted Quarterly GDP into values per month. Then we applied the moving-average method for the three quarters to convert to monthly data. However, with GDP data obtained in this way, the change is extremely small; thus, there is a possibility that the data may show multicollinearity with the constant term. Therefore, we removed the constant term from the estimate equation. The estimation result is as follows:

$$
\ln (\text { number of contracts })=-1.150 * \ln (\text { price })+2.027 * \ln (\text { GDP })
$$

$$
\text { No. of obs. }=44, \mathrm{R}^{2}=0.7964 \text {, Adj. } \mathrm{R}^{2}=0.7915, \mathrm{D} . \mathrm{W} .=0.238
$$

The coefficient of price is negative, while that of income is positive, which shows they fill the sign condition significantly.

\subsection{Estimation of consumers' sur plus}

Based on the demand function we estimated above, we found the increment of consumers' surplus as follows: First we estimate the theoretical number of contracts from charges in each month, in which we fixed the GDP as that of the standard month to remove influence from the change in GDP. Note that when estimating the theoretical number of contracts, we omitted the normalization by Cons umer Price Index. In addition, since the ADSL contracts are basically for the long term, we can consider the change in consumers' surplus relative to the yearly base. We can also see this through comparison with the annual sales. We estimate the consumers' surplus with the fixed annual price (12 times the price of the standard month), because, if there is no price change, the annual price would be 12 times charges of the standard month. With the number of contracts and the charges we presumed as described, we estimated the increment of consumers' surplus by using a trapezoid approximation on the numbers in each month. See Table-1 for the result of this estimation.

Table 1. Increment of consumers' surplus (million yen)

\begin{tabular}{|c||c|}
\hline Fiscal Year & Increment of consumers' surplus \\
\hline \hline 2001 & $31,285(\mathrm{US} \$ 2,844,000)$ \\
2002 & $7,071(\mathrm{US} \$ 642,800)$ \\
2003 & $18,458(\mathrm{US} \$ 1,678,000)$ \\
$2004(-\mathrm{Dec})$ & $2,137$ (US $\$ 194,300)$ \\
\hline Total & $58,951(\mathrm{US} \$ 5,359,000)$ \\
\hline
\end{tabular}

If March 2001 is set as the standard month, we can say that the consumers' surplus increased by 59,000 million yen. However, we should note that the amount of consumers' surplus is not simply comparable with the actual annual sales in the ADSL market, since we re-calculated charges into yen per $1 \mathrm{Mbps}$, in order to remove the influence from the improvement in connection speed.

\section{Factors promoting Japanese ADSL diffusion}

\subsection{Implementations and e vents of factors}

The important events that are commonly thought to be associated with the increase of the ADSL subscribers are presented in the following timeline: 


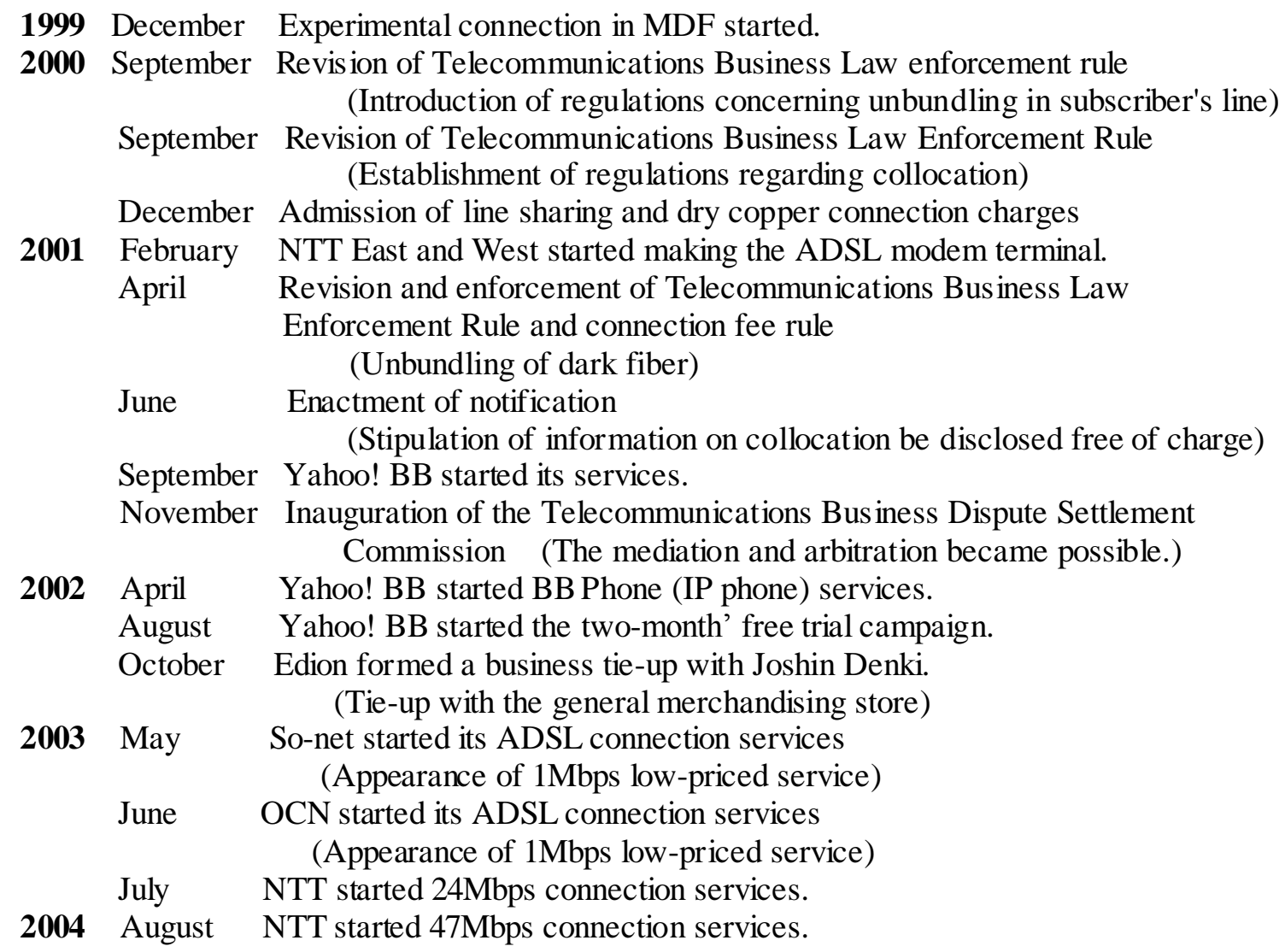

\subsection{Layers of factors}

We categorize the above mentioned factors into four groups: (a) deregulation factors; (b) competition factors; (c) technological factors; and (d) other factors. These consist of factors of the "first layer". For each first-factor, by observing policy implementations, market competition, and technological trends, we can identify more detailed sub-factors. For example, sub-factors of (a) include detailed policy measures related to (a-1) unbundling, (a-2) collocation, (a-3) connection charges, and (a-4) selection of lease or purchase of terminals. A number of sub-factors are also found for each of the other two factors. These make up the "second layer" of factors. Again, for each sub-factors, we can find more detailed factors. For (a-1) unbundling, detailed deregulations dealt with (a-1-1) dark fiber, (a-1-2) dry copper, (a-1-3) line sharing, and (a-1-4) connection shortening. For (a-2) collocation, (a-2-1) speedup of procedures, (a-2-2) opening of information, (a-2-3) collocation and dark-fiber, and (a-2-4) dark fiber are sub-factors consisting of the third layer. For (a-3) connection charges, (a-3-1) dry copper, and (a-3-2) line sharing are the third layer. Among (b) competition factors, (b-1) low charges strategy, (b-2) variety of services, (b-3) sales promotion at large discount stores, and (b-4) sales promotion on the street consist of the "second layer." For (b-1) low charges strategy, (b-1-1) price competition and (b-1-2) low price services (1Mbps) consist of the third layer. As for (b-2) variety of services, (b-2-1) free trail campaign and (b-2-2) on-site services form the third layer.

\subsection{Weight of each provider}

ADSL market share is indicated in Table 2. $80-96 \%$ of the ADSL market was occupied by the four main providers throughout the sample period. Therefore, for the AHP analys is, we asked only these four providers to assess the relative importance of factors. We then summed the score obtained from the four providers' replies, and calculated the importance of each factor. We must thus obtain the weight of each provider. For these weights we used the share of each provider for that that fiscal year. There is a small 
amount of market share occupied by other small providers; however, to simplify our calculation, the total market share is divided among the four major providers for the purpose of weighting.

Table 2. Market share of ISPs in the ADSL market

\begin{tabular}{|c|c|c|c|c|}
\hline & $2001 F Y$ & $2002 \mathrm{FY}$ & $2003 \mathrm{FY}$ & $2004 \mathrm{FY}$ \\
\hline NTI & 40.3 & 36.5 & 36.5 & 37.5 \\
\hline NTT East & 21.4 & 20.4 & 20.4 & 20.6 \\
\hline N11 West & 18.9 & 10.1 & 16.2 & 16.9 \\
\hline Yanoo! BB & 20.5 & 35.0 & 35.1 & 35.0 \\
\hline eAccess & 10.5 & 13.5 & 13.4 & 13.7 \\
\hline ACCA Networks & 9.2 & 11.7 & 10.4 & 9.5 \\
\hline Others & 19.1 & 4.7 & 3.9 & 4.3 \\
\hline
\end{tabular}

\section{Economic effect of factors revealed by AHP}

The results of the AHP analysis are summarized as Table 3 and Table 4. In Table 3 we see the largest absolute value of the economic effect is attributed to deregulation in FY 2001, at 10,298 million yen (US\$936,180), which corresponds with the fact that deregulations were implemented sequentially from the beginning of ADSL history. In the 4 years total, deregulation is the second biggest factor at 17,266 million yen (US\$1,569,600), with competition in the first place at 23,510 million yen (US\$2,137,273).

Table 3. Contribution of each factor

\begin{tabular}{|c||r|r|r|r|r|}
\multicolumn{1}{|c|}{ (million yen) } \\
\hline Factor & \multicolumn{1}{|c|}{2001} & \multicolumn{1}{c|}{2002} & \multicolumn{1}{c|}{2003} & \multicolumn{1}{c|}{ Total } \\
\hline \hline \multirow{2}{*}{ Deregulation } & 10,298 & 1,019 & 5,477 & 472 & 17,266 \\
& $(\$ 936,180)$ & $(\$ 92,630)$ & $(\$ 497,791)$ & $(\$ 42,910)$ & $(\$ 1,569,600)$ \\
\hline \multirow{2}{*}{ Competition } & 13,740 & 3,304 & 5,640 & 820 & 23,510 \\
& $(\$ 1,249,910)$ & $(\$ 300,364)$ & $(\$ 512,727)$ & $(\$ 74,545)$ & $(\$ 2,137,273)$ \\
\hline \multirow{2}{*}{ Technology } & 5,068 & 1,241 & 5,409 & 646 & 12,364 \\
& $(\$ 460,072)$ & $(\$ 112,818)$ & $(\$ 491,727)$ & $(\$ 42,182)$ & $(\$ 1,124,000)$ \\
\hline \multirow{2}{*}{ Other } & 2,180 & 1,777 & 1,931 & 192 & 6,080 \\
& $(\$ 98,182)$ & $(\$ 161,545)$ & $(\$ 175,545)$ & $(\$ 17,455)$ & $(\$ 552,727)$ \\
\hline \multirow{2}{*}{ Total } & 31,285 & 7,071 & 18,458 & 2,137 & 58,951 \\
& $(\$ 2,844,090)$ & $(\$ 642,818)$ & $(\$ 1,678,000)$ & $(\$ 194,427)$ & $(\$ 5,359,182)$ \\
\hline
\end{tabular}

Now let us study the percentage of each factor to the consumers' surplus in each year, which is denoted in Table 4. Deregulation accounted for 32.29\% in FY 2001, 14.41\% in FY 2002, 29.67\% in FY 2003, and $22.09 \%$ in FY 2004. The effect was largest in FY 2001. Regarding competing factor, its percentage was at its maximum in FY 2002 when Yahoo! BB started its services.

In these results, the effect of deregulation seems to be slightly smaller than expected by the actual change in the market. The reasons can be summarized as follows: (i) the system developments which were essential in ADSL services such as dry copper, line sharing and collocation were implemented in FY 2000. The providers surveyed here possibly included those initial three deregulation factors as given in their answers, which include only year from 2001; (ii) deregulations continued in FY 2001 and FY 2002 
when the ADSL services has spread considerably, but charges decreased at the same time, as seen in Figure 1. Therefore, the providers were not able to clearly separate the effect of deregulations; and (iii) the time when deregulations were implemented is the most distant from the time the providers were required to evaluate in the questionnaire, and there is a possibility that their memory was inaccurate. We also note some relations between deregulations and competition. Competition often progresses nearly simultaneously with the regulations that enabled that competition. Also, providers will request further deregulations even as competition progresses. In such cases, the questionnaire survey cannot effectively separate the two factors. There is a possibility that, faced with this choice, the providers assigned greater importance to competition, which stands out in their recent memory. These considerations may reflect the limits of the AHP, analysis which depends on the providers' subjective responses.

Table 4. Contribution of each factor $(\%)$

\begin{tabular}{|c||c|c|c|c|}
\hline Factor & 2001 & 2002 & 2003 & 2004 \\
\hline \hline Deregulation & 32.92 & 14.41 & 29.67 & 22.09 \\
\hline Competition & 43.92 & 46.73 & 30.56 & 38.65 \\
\hline Technology & 16.20 & 17.55 & 29.30 & 30.23 \\
\hline Other & 6.97 & 25.18 & 10.46 & 8.98 \\
\hline
\end{tabular}

\section{Conclusion}

By utilizing AHP, we heuristically derived the economic effects of factors promoting Japanese ADSL. As seen in Figure 1, there are three big jumps in its growth, namely, before June 2001, from September 2001 to January 2002, and from October 2002 to January 2003. From the results of our analys is, it follows that the first sharp increase was due to deregulations, the second jump was caused by market competition inspired by previous deregulations, and the third one by market competition. Thus, the AHP approach is thought to be a good methodology when usual regression analys is is somehow unable to use. In this case, the number of data is not enough to use econometric methods. The results derived by AHP, however, have some drawbacks: Significance of the result cannot be tested like those derived by econometrics. In order to apply for econometric analys is, we can use the panel data analysis, if the number of subscribers of each major ISPs. This is the next target of our research. The Japanese success of ADSL development is because of good cycle of deregulations and market competition: deregulations caused competition, while competition requested further deregulations. After all, subscribers (consumers) can obtain economic benefits. This is an exactly lesson learned from the Japanese ADSL experience.

\section{REFERENCES}

Eisner, J. and T. Waldon (2001) The Demand for Bandwidth: Second Telephone Lines and One-line Services," Information Economics and Policy 13, 301-309.

Kridel, D.J., P.N. Rappoport, and L.D. Taylor (2001) "An Econometric Model of the Demand for Access to the Internet by Cable Modem," in D. G. Loomis and L. D. Taylor (eds.), Forecasting the Internet, Boston, Kluwer Academic Publishers.

Sidak, G., C. Robert, and H. Singer (2002) "The Empirical Case Against Asymmetric Regulation of Broadband Internet Access," Berkeley Technology Law Journal, 17, 953-87. 